\title{
Analysis of the Relationship between a Learning Group and a Teacher at a Sciences Workshop of the Elementary School
}

\author{
Zenaide de Fátima Dante Correia Rocha1, Marcelo Alves Barros ${ }^{2}$ \\ ${ }^{1}$ Federal Technological University of Paraná, Londrina, Brazil \\ ${ }^{2}$ Physics Institute of São Carlos, University of São Paulo, São Carlos, Brazil \\ Email: zenaiderocha@utfpr.edu.br, mbarros@ifsc.usp.br
}

Received 13 August 2014; revised 10 September 2014; accepted 28 September 2014

Copyright (C) 2014 by authors and Scientific Research Publishing Inc.

This work is licensed under the Creative Commons Attribution International License (CC BY).

http://creativecommons.org/licenses/by/4.0/

\section{(c) (i) Open Access}

\begin{abstract}
This paper aims to investigate the dynamics of a learning group in a science workshop. The group selected for the research consisted of four students of the last years of elementary school I, 9 to 10 years old children. The data were collected by the teacher, upon recording the video lessons, at a public school in the municipality of Londrina-Paraná/Brazil. The theoretical basis used for the analysis and interpretation of the data is psychotherapy guidance, particularly the Theory of the Link Pichon-Rivière. Among the main findings, it is highlighted the link set between the group and the teacher, which contributed to a more stable organization among the members, including with the acceptance of a student who felt excluded. The contributions refer to the discussion of some relevant aspects of collaborative learning in order to promote and support the educational process through learning group in the classroom.
\end{abstract}

\section{Keywords}

Psychoanalysis and Education, Science Teaching, Learning Group

\section{Introduction}

The learning in group has currently presented itself as a prominent issue in the globalized world, considering that one of the areas of its application requires a collaborative work; an action involving several apprentices subjects, who are also issuers of knowledge.

Based on Vygotsky (1989), the group work may also be considered as a mechanism for measuring the learning of concepts, whose dynamics requires an "internal reconstruction of an external operation", arising from the 
social interactions. So that, Oliveira (1998) believes that culture is a "stage of negotiations" in which subjects share ideas and knowledge and reconstruct meanings. In our view of learning, concomitant with the theoretical thinkers submitted, the internalization process of knowledge takes into account the intersubjectivity, conveyed in the group processes, which is the representation of the psychic functioning of the group amid the intrasubjective nuances. Thus, there is a need of thinking about the group as potential mechanism of mediatiation of the collaborative learning process, once that through it, it is possible to socialize knowledge, interact and rebuild more elaborated knowledge.

Nowdays, researchers in the Science Teaching field, among which we highlight: Brown et al., 1989; Wheatley, 1991; Kirschner, 1992; Gil-Pérez, 1993; Duschl, 1995; Laborde, 1996; Rubtsov, the pud Laburú 1996a, 2005; Garnier, 1996; Barolli, 1998; Trumper, 2003; Barros \& Villani, 2004; Barros et al., 2005; Rocha, 2005; have emphasized the importance of the group learning as a privileged moment for the development and practice of intellectual abilities, likewise to promote the concept and deepen the students' understanding, enhancing the "insights" and solutions that would not be possible during individual learning, allowing students to take on different roles, confronting their prior knowledge and the inadequacy of their thinking strategies; so that, helping them to develop abilities necessary for the collaborative work, which is the way most people learn and work.

For these researchers, group work arises as a fundamental element of the methodologies based on teaching models that intend to bring close the learning situations of the activities of scientists. These methodologies aim to explore the dimensions of team work, organizing the teams and facilitating the interaction and communication between them. Opportunities are created in the group for discussions and argumentation in addition to experiencing the conflict between prior and new knowledge, and to foster an awareness of the inadequacy of reasoning strategies. Small groups provide opportunities for students to explain and justify their points of view, a process that stimulates the learning, because the ability of reasoning is one of the most important achievements of science education. In the process of telling others how to think about a problem, the students develop and refine their thoughts, going deeper on their understanding.

Relying on the cooperation, the apprentices go from the organization of their common actions for the solution of practical problems. Therefore, the collective forms of organization of the learning activity contribute to the acquisition of the theoretical content of the physical concepts (Laburú, 2005; Rubtsov, 1996a). Thus, the cognitive development cannot be conceived outside the social field in which the own actions mingle with social interactions, in a reciprocal and interdependent game (Garnier, 1996; Rubtsov, 1996).

The aspects highlighted about the team work show its importance in the teaching and learning process, making it necessary to promote a closer examination of the researches on the operating dynamics of work. Our work aims to contribute to it, as it attempts to uncover relationships of different kinds that are established in groups in teaching situations and understand the way they are structured to perform its tasks, likewise. We intend, so that, providing support for the teacher on planing the intervention in order to promote the operability ${ }^{1}$ of the group.

Under this perspective, the scope of this work is to investigate the working dynamics of a learning group in a science class of the Elementary Education I. It intends, mainly, to analyze the link between teacher and group established during the performance of the proposed educational activity. It also tries to answer the following question: How do the group and the teacher invest efforts in cooperation, overcoming the existing impasses in the group dynamics? For that, we tried to focus the difficulties that diverted students from the collective work and the challenges that drove them to the improvement as a learning group. It investigated the roles that they assumed in the group, the tasks assigned to each member and the relationship they established with the teacher.

It focuses on the group as a place of production of own subjectivities, and has the objective of understanding what may contribute to the proposition of interventions, by the teacher, toward the improvement on the levels of socialization and enhancement of the capacities of its students to work guided by a task.

\section{Research Methodology}

This research herein is qualitative (Bogdan \& Biklen, 1994) and it is a case study on the dynamics of a learning group in science at the Elementary Education I.

${ }^{1}$ According to Pichon-Rivière: a group that works in accordance with na operative dynamics is the one that has common objectives and goals in which all the members work as a group centered around the task. The activity is focused on the mobilization of the sterotyped structures, learning and communication difficulties, due to the accumulation of anxiety that is awaken by any change. One of the basic rules for operative groups may be translated as follow: "the greatest heterogeneity of the members of the group and the greates homogenity of the task correspond to higher productivity". 
This study has been carried out at a Municipal School of Londrina, in the state of Paraná, with students who participated of a Science Workshop, which is part of the Project Pedagogical Workshops².

The science workshop has been proposed to 12-year-old students at the last two years of Elementary School I. The dynamics of work consisted on the formation of three fixed groups of four students. It has been taken as object of study just a group formed spontaneously by two students of the fourth grade (CA, JE) and two from fifth grade (PE and JA), aged 9 - 10 years old.

The proposed activities consisted in making the students solve, actively, a problem of physical knowledge, that means, acting on an object and discussing the causes of the relationships which they established between their actions and the corresponding effects. This methodology tried to emphasize the initiative of the students and create opportunities for students to draw up arguments in order to defend their ideas and learn to respect their classmates' ideas (Carvalho et al., 1998); simultaneously, it intended to offer the possibility of forming working groups promoting the learning.

All long the data taking we used video recordings; classes were transcribed immediately after the meeting and accompanied by a report of an investigation carried out by the teacher, who was the researcher herself.

The course offered by the science workshop has happened in four months with a weekly meeting of $1 \mathrm{~h} 30$ min long, totaling 15 meetings about the physical knowledge. The classes took place in the Science Lab, a space where regular classes were held.

\section{Settings of an Operative Group and the Theory of the Link}

It has been used a theoretical framework based on psychoanalitical orientation in fundamented on operative groups, specially in the Theory of the Link Pichon-Rivière for an analytical reading of the research.

Pichon-Rivière (1995) features the group, and in this operating group case, as a restricted group of people, who are linked by constants of space and time and articulated by their mutual internal representation, it is proposed, in explicit or implicit form, to a task that is its purpose. Within this process, the person is seen as resulting dynamic in the interplay set between the subject and the objects, and their dialectical interaction through a dynamic structure called link. The link is defined as a complex structure that includes a subject, an object, and their mutual interrelationship with communication and learning processes.

The author sees the link as a dynamic structure in continuous movement, which encompasses both the subject and the object. The link is expressed in two psychological fields: internal and external. It is the internal that conditions much of the external and visible aspects of the conduct of the person. The learning process of external reality is determined by aspects or characteristics obtained from the internal reality, which occurs between the person and her internal objects.

It is relevant considering that the link is set by its totality of the person, which Pichon-Rivière interprets as a gestalt, in a constant process of evolution.

Another key-concept of the work of Pichon-Rivière is the role employed by the author in the theory of the link. According to him, our relationships with others are based on assumption and assignment of roles, which are taken consciously or unconsciously in a given social context. Regarding the concepts of role and link, Pichon-Rivière argues that these concepts are intertwined and, therefore a therapy focused on that should address the structure of the link, as well as the several roles, which are attributed by therapist and patient.

Hence, the role includes the status of the link. It is characterized for being transitional, with a determined function, which may appear in a given situation and in every person in a particular way. In other words, the way we handle certain situations will influence on our conduct, and it is what Pichon-Rivière assigned as the designation of roles. Among the main types of roles in a group it is highlighted: the spokesman, the scapegoat, the saboteur and the leader.

The spokesperson is the person who complains, for example, about the aspects related to difficulties in performing the task. These aspects are expressed because the person realizes and gets bothered about them. As it is disturbing, the person perceives them as being hers, and does not realize what is feeling. The person mentions them because in that moment she is the spokesman of the group difficulties, however, she expresses it as being only her difficulties. If the group faces the spoken contents and starts confronting and solving the group difficulties, the spokesperson becomes the leader of the task, the content that has been brought by her is heard by the

\footnotetext{
${ }^{2}$ The Pedagogical workshops project makes part of a program of the Municipal Education system of Londrina-PR. Its goal is to set the whole day education at the Elementary school I, through alternative workshops in an inverse to school, aiming to meet the demand of students that need pedagogic support, in an attempt to foster subsidy to improve the performance of these subjects on the teaching and learning process.
} 
group and from that comes up a solution to the dilemmas created, in order to avoid a global view about what prevents people of acting together. The group begins to behave in an intense cooperativity.

Although, if the group does not want to hear the spokesman, making him believe that the difficulty is of his own, the group begins to antagonize him in subtle or aggressive way and gradually, making of him into a scapegoat of the denied difficulty. They claim that the difficulty is his, expressing that his insistence disturbs the work of the group. The scapegoat expresses the content that is denied by the group and directed toward a person. The content brought by the spokesman is sharply denied and the group says it has nothing to do with him, but with the person whom he spoke to. They say that the content spoken is the opinion of the spokesperson and not of the whole group.

The person who tries to divert the group from the task and the common objectives to be achieved by everybody takes the role of spoiler, creating other needs as being the most important for the group at that moment.

The role of leader can excel in four characteristic types: autocratic, laissez-faire, demagogic and democratic or progressive. On the study of roles and links, different leadership styles stand out and may present more charismatic features and even some others more authoritarian, varying according to the introjected object, in other words, the type of content deposited in the person who takes this role or not, depending on links set in a given situation. The role is usually developed from a process of identification ${ }^{3}$, which always has a representational equivalent for leadership or for another type of role in assumption and assignment by the group. For example, the group demonstrates dependence on the role of leader to fight, flee or take conciliatory positions. Obviously, the leader gathers personal characteristics to manifest this behavior, however, the group itself takes the role of dependent. Both positions must be considered in the analysis of the process and as not the cause one another. Leadership, by itself, is considered a complex phenomenon that deserves study apart to be better understood.

To Pichon-Rivière (1994) there is an intimate relationship between the concept of roles and concepts of depositor, depositary and deposited. The depositor is the person or group that performs the projection. The deposita$r y$ is the external object on which the projection is located. And deposited is the transferred content. This meaning the link, allows both the construction of images that people internalize as experiences, as well as it is made in gathering commitments to perform certain task requested. The processes of projection and introjection ${ }^{4}$ of deposited contents can feature links between the depositor and the depositary of these contents. The contents may be, even builders of crystallized roles or not, it depends on what is attributed to the person or to the group and how they respond to the action of deposit, taking or denying it.

In this approach, Pichon-Rivière says that, from a situation characterized by stereotyping of roles and through the task, it presents another situation with functional leadership, which is expressed by the alternation of roles. To the extent that people acquire greater elasticity, being able to take the role of interpreters, so that, realizing themselves, then, a self-control, a self-feeding and a self-conduction of the group.

Figure 1 shows the theoretical relationship between the links and roles on the theory of Pichon-Rivière (Rocha, 2005).

\section{The Dynamics of the Group Investigated}

In order to improve the analysis of data under the theory used, it has been opted by making a cutout of the sciences workshops project, reporting one of the educational activities proposed. So that, the activity of the sixth meeting, which aimed to discuss the existence of air and space used by it. The challenge consisted in putting a sheet of paper into a glass and sink it in a container with water, without wetting the paper (Carvalho et al., 1998).

In previous lessons, one of the group members (JE) kept, with higher frequence, a less privileged role in the group, he was the last to make attempts to solve the challenge. He did not interact with the other members and showed more difficulties to understand the ways of solving the challenges posed by the teacher to the group. Colleagues would ignored him and he realized that. At the beginning of the sixth meeting, the group dynamic seemed similar to the previous meetings; JA led in partnership with CA, i.e., he set the rules for organizing at

${ }^{3}$ According to the psychoanalysis kleinian, the identification consists in a defense mechanism. It is a relation in which the object, such as it is gives in to an object that is the extend of the ego. In this meaning, it consists of a narcisist relation of the object, in other words, the ego is connected to a part that seems to be out, in the "object", but, in fact, unconsciously, is a part of himself (Simon, 1996).

${ }^{4}$ As the identification, the projection is with the introjection one of the defensive conduct. While the projection is the fact of attribute to external objects, characteristics, intentions or motivations that the subject or group do not know in itself; the introjection is the incorporation or assimilation, by the subject or group of characteristics or qualities that come from an external object, from the external world (Bleger, 1989a). 


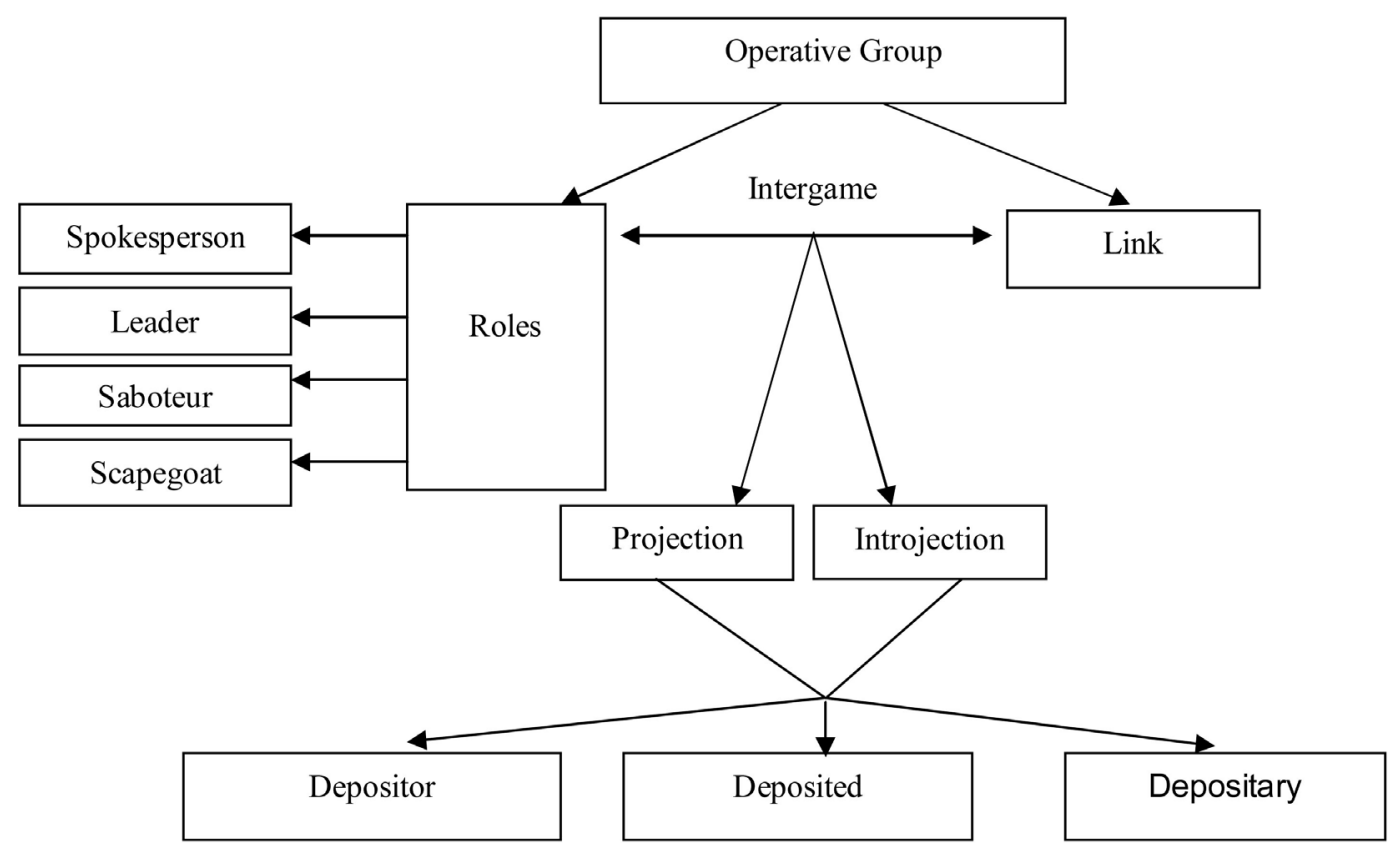

Figure 1. Outline of the structure of links and roles for Pichon-Rivière's theory.

tempts and called the other members (EP and JE) to work. Meanwhile, JE always used to be the last in attempting. In the episodes presented below, it is highlighted the very moment that the group began to work more cooperatively, supporting the difficulties of the group its members and sharing common goals, by overcoming the impasse on the exclusion of the student JE from the collective work and his respective progress in the construction of meaning in the learning process of sciences.

\subsection{The Initial Invitation}

Initially the teacher invited the group to work cooperatively in solving the activity, explaining his desire to accept contributions from the ones who were being excluded.

Prof.: "In our lesson today we will try to solve a challenge. We have a pot with water and you will receive this plastic glass. You can pick it up and note the type of glass. The challenge is: how do we do to put this paper into the glass and sink the glass in a basin with water, without wetting the paper? You can do it the way they wish, talk among yourselves, discuss the rules and think about some ways to solve this challenge. But it is not only you or him, the whole group should discuss and explain this”.

In the first meeting, the teacher envisioned to arise the interest and participation of students, although she did not expressed her purposes for the group. At this meeting, on the contrary, the teacher reported to the group how her group collaboration favored the quality of work achieved.

\subsection{Reporting an Implicit Pact}

Since the beginning of the course, the students JA, CA and PE constituted a sub-group; in turn, JE was excluded from the discussion. JA became the first leader of the group able to establish an identification among its members in order to be a good group for the teacher. At the same time, there was also the establishment of an implicit pact of the group in not letting the individual aggressiveness disturb the teamwork. However, in this sixth meeting the student JE reported this pact with the explicit exclusion of the impasse.

JA: “Let's screw the paper! Do you agree JE? Do you, PE? CA do you agree?”

CA: "Let's decide on the rules first. Whoa there! calm down!". "First" (Referring to student JA).

"Second" (Referring to the student PE). "Third" (Pointing to herself) "and fourth.” (Referring to student JE).

JE: "Yeah, I'm acctually the last!" 
Realizing the placement of JE and his dissatisfaction regarding the other members of the group, the teacher approached and asked for JE.

Prof: "Have you had any problem today?"

JE: "No!"

Prof.: "Is it about your group?"

JE: "Yes."

Prof.: "What is that?"

JA: "But itwas with us? With all of us?"

JE confirmed it was about the group nodding.

Prof:. "-So apologize to him!"

JA: "But what?"

After the teacher's intervention, the students CA and JA talked to JE while PE resisted to the group decision, with suspicious eyes, not expressed verbally, however, expressed in gestures not agreeing with the care offered by JE and the others likewise.

CA: "What is that?"

JA: "What happened?"

JE: "-Since the beginning!"

Prof:. "What has happened?”

JE: "See, they are already saying that they do not want me to go in their group."

JA: “Today, I have not spoken, teacher. It has been a while, yet!”

JE: "-The day I joined the group he said he did not want me to join in their group."

JA: "No teacher, but you know why I said that? It's because he would argue with everyone, we kept telling him to stop, but he did not. Then all of a sudden I got tired, teacher, and said, but it has been a long time. (...) I just got angry when he was disturbing the group, in fact, everyone ... hence I said.”

\subsection{The Construction of a New Contract}

After JE showing his dissatisfaction about the group, with the help of the teacher, the problem was faced by everybody and the group overcame it, moving on to a joint production. Students reflected on the discontent of the subgroup and showed the discomfort with the attitudes of JE and, that member has also shown to have reworked his actions, as in face of new dynamics during the resolution of the task presented collaborative attitudes. The exclusion of JE was overcome and students committed themselves to the construction of new rules, imposed conditions and commitments for changes in an attempt to support to the student JE, according to the following statements:

EP: "If he does not do anylonger,, not keep arguing, I .... okay."

JA: "That day we talked to him, he improved. Although, he continued doing the same thing again, and it has been so long since I said that, and qhy is he is like that today?"

CA: "But was it that day when we decided who would start solving the challenge?"

This student remembered the beginning of the activity when they decided on the order to conduct the trials. JE remained silent for a moment with his head bowed as they talked and then when CA reinforced PE speech, he raised his eyes intently watching the proposal that seemed to be shared by JA and PE.

CA: "If he does the activity and stop complaining... We could let him try once more."

The student was referring to the fact of giving to JE once more the opportunity of attempting to solve the challenge. And turning to JE she asked:

\section{CA: “Do you accept JE?”}

JE nodded that he accepted. Thus, the student JA called the group to work again highlighting the trials and experiences of JE.

CA: "So, now I want to see the way he wanted to talk at that time about the experience." 
When they began to talk, the causes of the problem appeared and, through the intervention of the teacher, the situation was gradually stabilized. But, JE, still had some trouble to expose herself, then the teacher realizing her fear and weakness, suggested:

Prof: “Try, even if it to fail. It's just for us to see how your suggestion would be, as you said, no matter if water gets into that, but you are even trying and learning from it, aren't you? Because even some water gets some water, we can compare why water enters and why would not otherwise enter.”

Shortly thereafter, JA called the group on an attempt to jointly host JE.

JA: "Let's do the following... After trying it on his way, we begins to speak: I talk about that in a way, then in case you have an idea you tell us?"

With the support of the group and the teacher, JE, confident, returned to perform the task actively, explaining their actions and demonstrating different attempts.

CA: "You'd better not bend that way."

JE: "It is because if you do not fold it does not fit in the glass. It may be that this way works out!"

As mentioned previously, the student JE did not risk exposing his strategies of work for the members of the group, but after reworking the impasse between them, this student started to improve on the learning process in science: He justified his actions, analyzed better the results obtained, and gradually conquered his space in the group. By provoking dialogue, conducted by the teacher aiming to form a group, the changes deemed necessary for the implementation of a new work environment, more supportive and harmonious occurred in face of the impasse installed. At this meeting, it was necessary a group destabilization for the group felt the need to reflect on the reaction presented by JE. It was necessary that JE paralyzed and, in such a way, confronted the group in order to make the changes. Therefore, the dilemma experienced by the members of the group was appropriate in that situation in which the group is found, since it contributed to its improvement; an aspect that favored its evolution in operational terms. The teacher let the group talk and kept the balance as a coordinator, guiding the work. She also provided support for overcoming the problems without creating dependency in order to let the group take responsibility for their actions.

At the end of the lesson, the group was more focused on solving the challenge and can progress in learning science as well as in social relations issued by each of the members on behalf of a collaborative learning. Considering the following, the new group setting for solving the challenge proposed in this class.

Prof.: "But why isn't it wet?"

JE: "Because we put it slowly and then fast."

EP: "No, teacher, the the little glass is already with air inside and when you put it in there, there's no air and the air is there taking up space."

JA: “-Wouldn't it be wet...? Oh, there's no air inside the glass. When we put it, it cannot come out, then when we're sinking it, how will the water enter if the air is in there? The air will not be able to go out by here!”

All of them watched as JA talked and showed the experiment.

JA: "-We can not try another way now?"

JE: “yes you can!”

JA: "-Oh, let me give it a try! I think it will get wet, even though... I have my doubts, because I think that this way it may work."

While JA prepared the glass with screwed up paper in the bottom, the others were watching. All of the other members kept following JA, while placing the glass slowly dipped into a bowl, but with the edge facing up. Then the glass was filled with water and he smiled to the group members, who said in chorus: "-Wetted". The teacher, who also accompanied everything, asked them:

Prof:. "-Why has it got so wet like this?”

JE: "Because if it is put like this the water will.” (Demonstrated again with a glass facing to the side).

JA: "-I know why. Because he put a half and then the water started coming in and the air was going out 
to enter the water.”

EP: "-The air is weaker than the water."

JA: “-Look Here! It cannot be done like that (covers with the hand the glass) in order to avaid the air dto come out."

EP: "Hey teacher, can it be done this way?"

Prof.: "-How is the challenge? Read the box..."

They read and PE says: "So it can be done in any way!"

Prof.: "And then, have you finished?"

JE: “No!”

EP: "Look teacher, the water went in!"

Prof.: "Why?"

EP: "Because there are some air bubbles coming out!"

JA: “-yes, that time it did not come in, and now the water entered because the air went out."

Prof.: “-I wish you four talked, because I guess you are not thinking the same things.”

JA: “-Why do you think JE?”

JE watched carefully CA student who at that moment put half of the paper inside the glass and screw and stuck, and the other half on top of the glass. Following this, the student turned the glass and sinked into the bowl with water holding the top that was sealed by paper. The paper that was not wet inside, so they reported success in solving the challenge for the teacher and repeated the experiment several times in this same way. Then the teacher asked them: “-And why the water does not enter?”

PE: “-It is because there is air inside teacher, and puts business here (showing the glass) does not come out."

Prof.: “And when the air comes out?”

Students responded in chorus: "Hence, the water enters!"

From the data collected it can be inferred that the group experiences and teaching mediation allowed a evolution on the thinking and in the action of these students in reelaborating their conceptions of physical knowledge in view of solving the problem. The group dynamic aspects of operability when its members established a dialogic relationship in carrying out the task. Another important element to be highlighted, by reading psychoanalytic pichoniana, is the configuration of the group as a place of production of own subjectivities; dynamics that contributed to the proposition, by the teacher, interventions toward an evolution on the levels of socialization and strengthening the capacities of their students to work guided by a task. In this case study, it is relevant to mention a promising aspect of learning of concepts in more elaborate levels, so that the group remained focused on collaborative learning, raising to upper levels the links that each of the students had been setting with knowledge, teacher, as well as with the other group members.

\section{Final Comments}

The study herein aimed to uncover subjective relationships set among the participants of a learning group during the performance of a Science Workshop for elementary school students and, at the same time, understand the way they were structured to perform the tasks, through lessons oriented by the teacher. We tried, therefore, to provide support for the teacher to plan the intervention in order to facilitate the group work. This research, in special, intended to identify some subjective conditioning that featured the different positions that students took in face of the knowledge and to teacher during the performance of physical knowledge at an office of science in Elementary Education I. Therefore, it could contribute to the teaching practice, especially regarding the teaching and learning process that promotes the group work. Based on psychoanalytic theoretical framework of Pichon-Rivière we believe that our results point to some elements that allow a better comprehension of the work of the learning groups and provide suggestions for its organization in the classroom, in order to enable the improvement of science teaching by the subjectivity.

Earlier, the group expressed negative links, at the point of rejecting a member. Acting with contempt for the actions of JE, the members of the subgroup left him out in the begging, but later explained the exclusion of the student verbally. 
It is important to mention that at the moment that the teacher changed the intervention, inviting the group to work more collaboratively, the group also changed. The contents deposited by the teacher in the group undertook everybody to a more effective communication. From that moment on the teacher coordinated the group and proposed a reflexive action, allowed them to show their anxieties, explained their cognitive and affective problems providing students space for working together in an attempt to solve their conflicts, in order to facilitate the communication and consequently improve the learning of sciences.

During the activity, the teacher made interventions in an attempt to foster greater group interaction, tried to promote a cooperative learning and, in some moments, she preferred to let the students of the group more comfortable to talk together and solve their problems without her excessive interference. At certain point, JE had a problem: the exclusion, i.e., the implicit content and the core of the problem to the group formation. Given this situation, the teacher was sensible to present information, solving the issue set in that context, making appropriate decisions without taking advantage of any of the students envolved. Nevertheless, the first action made for this case was checking it, then the reading of the events, and finally questioning intentionally to challenge group.

To verify the situation, the teacher used questioning who invested in "listening" for all of the involved ones. Attempted to understand the context of the situation that envolved them, and the causes and effects of the conflicting relationship generated due to the circumstances presented, likewise. As she reported what happened, the group members expressed what they thought, facilitating the elaboration of their anxieties and resistances.

The role assigned to the teacher was double. In one hand, she inspired confidence, not much for knowing all the answers, but knowing how to conduct a process of resolution of cognitive, affective or emotional problems by providing some stability to the group. In other hand, while she decided on the task performed and recognized the competence of the group. The group members were callaborators in the process, mobilizing plasticity and clarification of roles that could facilitate the learning for thinking together towards solving the problems presented.

According to Souto Asch (1990), group representations arise from the interaction. The group in the process goes reaching different levels of relationship and organization. Its result is not linear, but spiral, and happens by the confrontation and resolution of the several conflicts that follow and are structured on another. When a group (re)elaborates its lived experiences, there is the group evolution, rightly promoted by the occurrence of conflicts that arise from moments, in which the components are building interrelationships that result in common findings to the whole group. In the learning process, the subject increases the integration and feelings of belonging to a group, participating in conflict resolution dynamics of the class. The group goes through different basic assumptions and shares emotional states, progressing continuously in their own learning process, evaluating failures and difficulties. This spiral that happens along the way the group process must be closely monitored by the teacher as an important integrating element of the learning process.

Even though, two factors must be taken into account. Firstly, the nature of the linkages established can vary greatly from one subject to another, in other words, the links are particular ways of reconstructing the reality and are up to the idiosyncrasies. Secondly, one of the characteristics of the links is that they are dynamic and interdependent, that means, a change in a link has repercussions in others. That explains why a change in the methodology of the class can cause a change in the relationship of the student, for example, with knowledge. Moreover, it also explains why a change in a particular link (the task of working in group) may not be enough for a significant change, in case other links have not been affected (for example, teacher-student relationships and student-student).

In a nuthshell, based on the results presented here, it is possible to point out some considerations for the teachers training, highlighting the need of an educator "knowing how to recognize" that the links that tie her students at a certain satisfaction, opening room for their subjective choices. The teacher's interventions should occur in order to point to the group as the work has been done, specially, how it strives to work under the difficulties presented by its members.

The support that the teacher may offer group acquires meaning only in the moments in which he interferes on the changes and walks with the group in order to overcome their difficulties and to organize in a more stable form. Somehow, the teacher has to anticipate the perception that effective collaboration among the members may come with the development of group work.

From this perspective, whose focus is to think and act in the face of uncertain situations mobilized by the group of students, the teacher's role, at the beginning of a group refers to the rules of his teaching process, in other words, if he can launch an effective invitation at unconscious level there will be more chances to meet the 
need for security that the group demands. So, for that, the teacher should first try to hear the students' complain, not in order to solve them promptly — what would produce a state of dependence—or would disqualify them, but, pay attention to these complaints instead and return them to the group in a more elaborated way.

One point that deserves a specific analysis is the dependence of the group of a founder or leader. Early in the development of the group, the leader with authority for acting, setting objectives, tasks, allows the group may reach their achievements without the need of exposing themselves. However, remaining in this position the group seems to crystallize the assumption about their inability of carrying out each member's own learning and irremediable need to depend on someone able to provide what you need.

Thus, if the leader accepts to manage the dependency, initially the effect may be positive, as it allows the group to be structured and leaving the seriality. On the contrary, if the leader refuses this role, the group will feel frustrated and abandoned; a feeling of insecurity will possess the participants and the group may be separated. However, as the time goes by, the dependency becomes an obstacle to the development of the group because it prevents the emergence of the creativity of its members ${ }^{5}$.

If our interpretation is correct, the "listening" to the teacher should focus on both the group situation of the students as what they know. It is important to stress that the teacher's intervention must be to orientate and discuss the production of students as a result of the work of the group and not just of the work of the members; he should not forget that the task is being performed in groups, talking to the group and not only with some of its members. Thus, by assuming that it is involves the work of the group, it will be more likely to be heard by the students, being recognized as a guide in whom they can trust and who will offer contributions.

The teacher's interventions should occur in order to point to the group how the tasks are compatible with the knowledge of the majority, in other words, with their chances of satisfaction in learning how the work is being carried out collectively and how the group strives in working on the difficulties of its members. The support that the teacher may offer to the group itself, only acquires meaning for the group in moments when the teacher works on the changes that the group suffers, and walks with him in order to overcome their difficulties and to organize $t$ in a more stable form. Such actions are understood here as important strategies to encourage and enable the construction of knowledge in science. Thus, the dynamics designed by the group aggregates, respectively, the "instructions" of the teacher about what she conceives as sciences, the sciences and how to learn why learning sciences.

A strategy that seems plausible to our results, it consists in the teacher stimulating the flow of ideas and concerns among students, as well as causing mobility roles. In this sense, the teacher may return to the group a question asked by a student (rather than giving the answer ready to pronounce a "do not know"), encouraging debate among them and allowing them to learn respecting the differences and particularities of each, as observed in this work while solving the challenge. It can also be requested that certain activities be answered by some members, respecting the knowledge of each promoting a successive socialization of results.

According to Barolli (1998), when the teacher acts this way his interventions get a new quality as pointing and revealing the way the group is structured in different moments of its work. It seems that it is how it can contribute to the strengthening of the group and hence for the development of its autonomy. Through this joint effort that students are prepared to endure the difficulties of development and all that entails efforts to learn. If the teacher makes interventions that are aimed solely to suit individual difficulties, could reinforce assumptions that are more active and thus, fail to contribute to the idea of cooperation, while successful form of participation and individual growth, be incorporated by group.

It is up to the teacher to help students work cooperatively, providing support for this process, by identifying the elements that characterize each stage of the organization of the group to face its task, in special, in this work the task of learning sciences. Although, it is necessary that the process of group development occurs in a long term and has some stability in their composition.

From the theoretical approach used, we highlight its importance in understanding the role of subjectivity and unconscious aspects of the teaching and learning process. This framework articulates concepts of group psychoanalysis, in particular, the theory of link Pichon-Rivière, which characterizes the intersubjective links, the roles and the task to be performed by members of a group.

\footnotetext{
${ }^{5}$ We must highlight also the existence of a functional dependence, which arises as necessary relation in moments that the group, in order to achieve their objectives and complete the task, requests a guiding or a piece of information. This dependence is compatible to the advanced levels of operability of the group, once it does not prevent neither the learning, nor the task, on the contrary it facilitates, and answers to a rational quest for means to achieve the ends.
} 
In interpreting this situation experienced by the teacher, from the point of view of subjectivity, new questions are posed, and concern uncertainties, instabilities and complexities intrinsic to the relationship of teaching and learning. Undoubtedly, the introduction of subjectivity in research on teaching and learning points to the complexity of the teaching work, with difficulties and increased risk of failure effects, and possibly with loss of control of its production. The teacher who does his work like this will be susceptible to ambiguities, resistances, successes and failures arising from his profession. In other words, he will have to abandon the illusion of having absolute power over their students and not being able to control rationally all the teaching situations.

We believe that the psychoanalytic theory can help decisively to focus on the core of the impasse and the possibility of significant change. According to Barros et al. (2005), we also believe that our analysis can help teachers realize and locate any eventual conflicts in their classrooms faster and more accurately, not for providing a theoretical standard directly applicable, but for present different cases that offer hints and tips to keep you alert during the teaching practice.

It has also to be considered that the psychoanalytic framework contributes to rethinking educational practices in order to assist teachers in developing professional skills to handle with situations of impasses in classroom. Thus, it takes into account the totality of the subject, which, in an autonomous and non-arbitrary way, mobilizes his professional knowledge on the decision-maker and on a more complex exercise of the profession.

\section{Acknowledgements}

To the Board of Post Graduation Studies and Research of the Universidade Tecnológica Federal do Paraná UTFPR-Londrina Campus for supporting the publication.

The National Council for Scientific and Technological Development (CNPq).

\section{References}

Asch, M. S. (1990). Didáctica de lo grupal. Argentina: Instituto Nacional de Perfeccionamiento y Actualización Docente (INPAD). Ministerio de Educación y Justicia.

Barolli, E. (1998). Reflexões sobre o trabalho dos estudantes no laboratório didático. São Paulo: Faculdade de Educação, Universidade de São Paulo.

Barros, M. A., \& Villani, A. (2004). A dinâmica de grupos de aprendizagem de física no ensino médio: Um enfoque psicanalítico. Revista Investigações em Ensino de Ciências, 9, 115-136.

Barros, M. A., Villani, A., Rocha, Z. F. D. C., \& Barolli, E. (2005). Analisando a dinâmica de um grupo de aprendizagem em ciências no ensino fundamental. Enseñanza de las Ciências, Volume Extra, 1-5.

Bleger, J. (1989). Temas de psicologia: Entrevista e grupos. São Paulo: Martins Fontes.

Bogdan, R., \& Biklen, S. (1994). Investigação Qualitativa em Educação. Uma Introdução à Teoria e aos Métodos. Lisboa: Porto Editora (Coleção Ciências da Educação).

Brown, J. S., Collins, A., \& Duguid, P. (1989). Situated Cognition and the Culture of Learning. Educational Researcher, 1, 32-42. http://dx.doi.org/10.3102/0013189X018001032

Carvalho, A. M. P., Barros, M. A., Gonçalves, M. E. R., Vannucchi, A. I., \& de REY, R. C. (1998). Ciências no Ensino Fundamental: O Conhecimento Físico. Editora Scipione.

Duschl, R. (1995). Más allá del conocimiento: Los desafíos epistemológicos y sociales de la enseñanza mediante el cambio conceptual. Enseñanza de las Ciencias, 13, 3-14.

Garnier, C., Bednarz, N., \& Ulanovskaya, I. (1996). A aprendizagem como atividade coletiva: Escolha e organização das atividades segundo as correntes soviéticas e sócio-construtivistas. In Após Vygotsky e Piaget (pp. 207-222). Porto: Perspectivas social e construtivista, Escolas russa e ocidental, Artes Médicas.

Gil-Pérez, D. (1993). Contribución de la historia y de la filosofia de las ciencias al desarrollo de um modelo de enseñanza/ aprendizaje como investigación. Enseñanza de las Ciencias, 11, 197-212.

Kirschner, P. A. (1992). Epistemology, Practical Work and Academic Skills in Science Education. Science \& Education, 1, 273-299. http://dx.doi.org/10.1007/bf00430277

Laborde, C. (1996). Duas utilizações complementares da dimensão social nas situações de aprendizado da matemática. In Após Vygotsky e Piaget (pp. 29-46). Perspectivas social e construtivista, Escolas russa e ocidental, Porto Alegre: Artes Médicas.

Laburú, C. E. (2005). Seleção de Experimentos de Física no Ensino Médio: Uma investigação a partir da fala de professores. Investigações em Ensino de Ciências, 10, 1-19. 
Oliveira, M. K. (1998). Pensar a Educação: Contribuições de Vygotsky. In J. Antonio (Ed.), Castorina (pp. 51-84). Piaget-Vygotsky: Novas contribuições para o debate, São Paulo: Ática.

Pichon-Rivière, E. (1994). O processo grupal (5th ed.). São Paulo: Martins Fontes.

Pichon-Rivière, E. (1995). Teoria do Vínculo (5th ed.). São Paulo: Martins Fontes.

Rocha, Z. F. D. C. (2005). Análise da dinâmica de um grupo de aprendizagem em ciências no ensino fundamental. Dissertação, Mestrado em Ensino de Ciências e Educação Matemática, Londrina: Universidade Estadual de Londrina.

Simon, R. (1986). Introdução à Psicanálise: Melanie Klein. São Paulo: EPU.

Trumper, R. (2003). The Physics Laboratory: A Historical Overview and Future Perspectives. Science \& Education, 12, 645670.

Vygotsky, L. S. (1989). A formação social da mente: O desenvolvimento dos processos psicológicos superiors (3rd ed.). São Paulo: Martins Fontes.

Wheatley, G. H. (1991). Constructivist Perspectives on Science and Mathematics Learning. Science Education, 75, 9-21. http://dx.doi.org/10.1002/sce.3730750103 
Scientific Research Publishing (SCIRP) is one of the largest Open Access journal publishers. It is currently publishing more than 200 open access, online, peer-reviewed journals covering a wide range of academic disciplines. SCIRP serves the worldwide academic communities and contributes to the progress and application of science with its publication.

Other selected journals from SCIRP are listed as below. Submit your manuscript to us via either submit@scirp.org or Online Submission Portal.
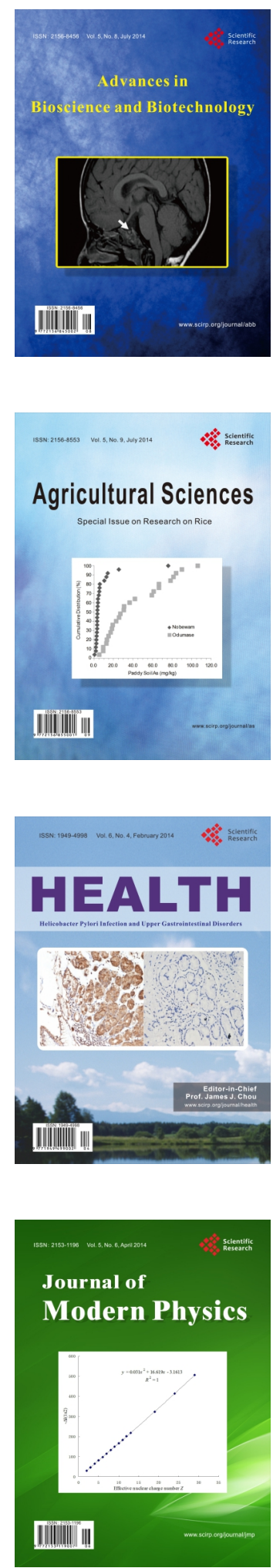
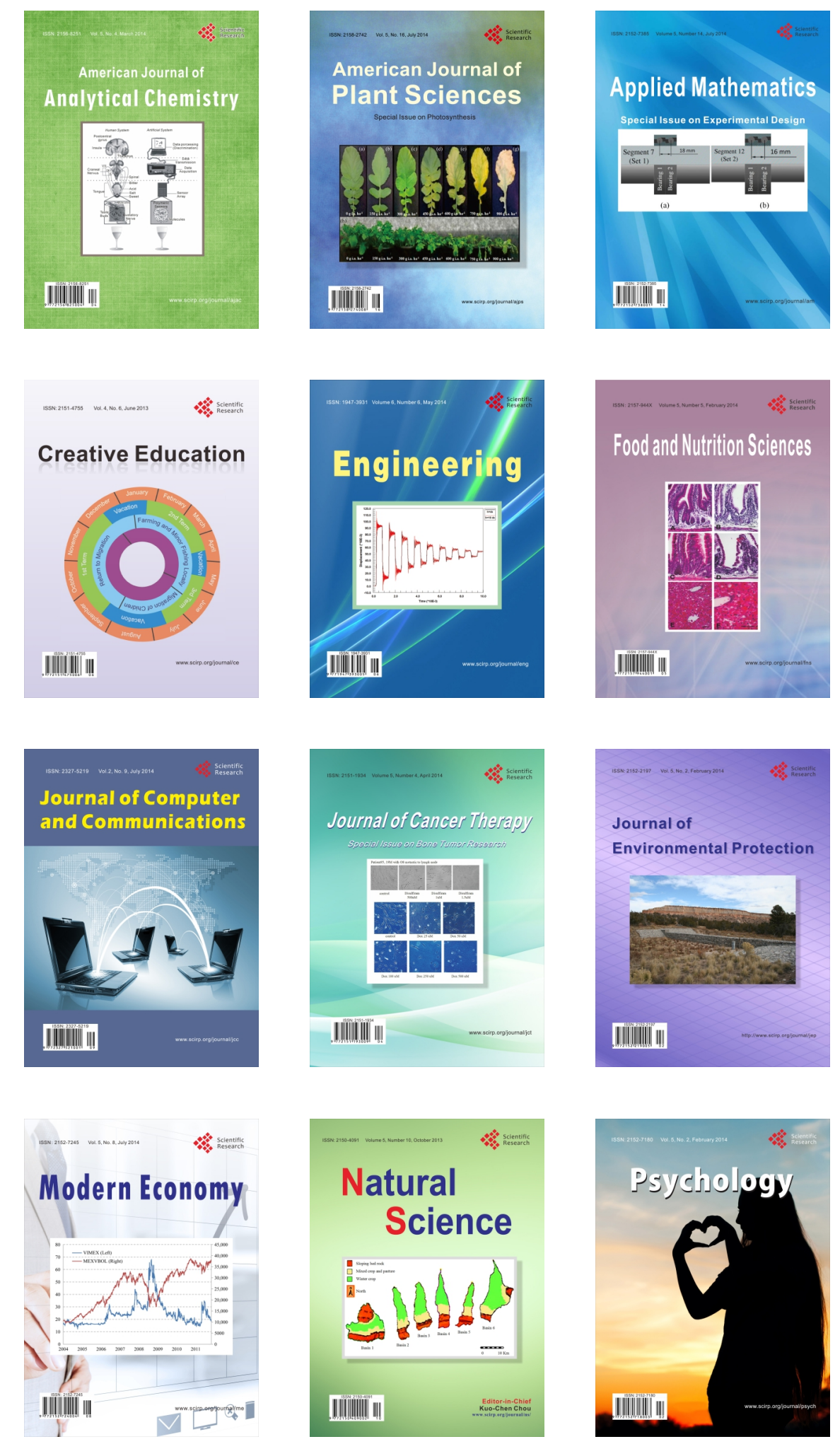